\title{
Hypervalent siloxane derivatives. An alternative to Stille and Suzuki couplings*
}

\author{
Philip DeShong ${ }^{\dagger}$, Christopher J. Handy, and Molly E. Mowery \\ Department of Chemistry and Biochemistry, University of Maryland at College \\ Park, College Park, MD 20742 USA
}

\begin{abstract}
Siloxane methodology is extended to couplings with iodo- and bromoanilines, hindered arylbromides, and substituted siloxanes as substrates. Additionally, initial studies with 5-bromoindole and other heteroaromatics suggest that the siloxane-mediated cross coupling methodology will also be applicable in these systems.
\end{abstract}

\section{INTRODUCTION}

Palladium-catalyzed cross coupling reactions have been developed as a versatile tool for the formation of carbon-carbon bonds [1-4]. Traditional methods used to accomplish this type of transformation include the Stille and Suzuki reactions [1-6]. Recently, silicon-based reagents have been reported to effect these type of cross coupling reactions [7-14]. Results from our group, Hiyama, and others have shown palladium-catalyzed, fluoride-promoted reactions of silicon derivatives to be an attractive alternative to the Stille and Suzuki coupling reactions.

Initially, we demonstrated the ability of siloxane derivatives to cross couple with aryl iodides, electron-deficient aryl bromides, and allylic benzoates in excellent yields [7]. A more general palladium catalyst/ligand system has been developed that activates a wide range of aryl bromides, including bromopyridines and bromothiophenes [15]. Additionally, the addition of Buchwald's ligand [16-19] allowed the couplings of aryl chlorides to proceed with good yield [15].

\section{RESULTS AND DISCUSSION}

We examined a variety of substituted anilines as substrates in cross couplings with siloxanes (Table 1) and found that $p$-iodoaniline (entry 1) underwent reaction in good yield, as did $p$-bromoaniline (entry 6). Additional attempts with acetamides and sulfonamides (entries 4, 5, 8, and 9) proceeded successfully, as did couplings with $N, N$-dimethyl-p-iodoaniline (entries 2 and 3).

Our results also indicate that anilines couple in good yield regardless of the position of substitution on the aromatic ring (entries 1, 10, and 11). This result illustrates the general nature of the siloxane-mediated cross coupling with electron-rich anilines. The versatility of the reaction is further demonstrated with the successful coupling of electron-deficient substrate 1-bromo-2-nitrobenzene (entry 12).

A second area of investigation involves the steric tolerance of this methodology. When subjected to typical coupling conditions, 2-bromo- $m$-xylene (1) underwent cross coupling with phenyltrimethoxysilane to afford heterocoupled adduct 2 in $85 \%$ yield (Scheme 1).

\footnotetext{
*Lecture presented at the $13^{\text {th }}$ International Conference on Organic Synthesis (ICOS-13), Warsaw, Poland, 1-5 July 2000. Other presentations are published in this issue, pp. 1577-1797.

Corresponding author
} 
Table 1. Substrate studies.

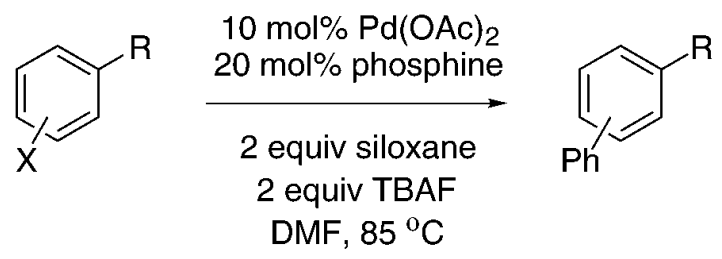

\begin{tabular}{|c|c|c|c|c|c|}
\hline Entry & $\mathrm{X}$ & $\mathrm{R}$ & Phosphine & Siloxane & Yield \\
\hline 1 & 4-I & $\mathrm{NH}_{2}$ & $\mathrm{PPh}_{3}$ & $\mathrm{PhSi}(\mathrm{OMe})_{3}$ & $95 \%$ \\
\hline 2 & $4-\mathrm{I}$ & $\mathrm{NMe}_{2}$ & $\mathrm{PPh}_{3}$ & $\mathrm{PhSi}(\mathrm{OMe})_{3}$ & $69 \%$ \\
\hline 3 & $4-\mathrm{I}$ & $\mathrm{NMe}_{2}$ & $\mathrm{PPh}_{3}$ & $\mathrm{PhSi}\left(\mathrm{OCH}_{2} \mathrm{CF}_{3}\right)_{3}$ & $85 \%$ \\
\hline 4 & $4-\mathrm{I}$ & NHAc & $\mathrm{PPh}_{3}$ & $\mathrm{PhSi}(\mathrm{OMe})_{3}$ & $70 \%$ \\
\hline 5 & $4-\mathrm{I}$ & NHTs & $\mathrm{PPh}_{3}$ & $\mathrm{PhSi}(\mathrm{OMe})_{3}$ & $65 \%$ \\
\hline 6 & $4-\mathrm{Br}$ & $\mathrm{NH}_{2}$ & $\mathrm{PPh}_{3}$ & $\mathrm{PhSi}(\mathrm{OMe})_{3}$ & $48 \%$ \\
\hline 7 & $4-\mathrm{Br}$ & $\mathrm{NH}_{2}$ & $\mathrm{P}(o-\text { tol })_{3}$ & $\mathrm{PhSi}(\mathrm{OMe})_{3}$ & $78 \%$ \\
\hline 8 & $4-\mathrm{Br}$ & NHAc & $\mathrm{P}(o-\text { tol })_{3}$ & $\mathrm{PhSi}(\mathrm{OMe})_{3}$ & $77 \%$ \\
\hline 9 & $4-\mathrm{Br}$ & NHTs & $\mathrm{P}(o-\text { tol })_{3}$ & $\mathrm{PhSi}(\mathrm{OMe})_{3}$ & $72 \%$ \\
\hline 10 & $3-\mathrm{I}$ & $\mathrm{NH}_{2}$ & $\mathrm{P}(o-\text { tol })_{3}$ & $\mathrm{PhSi}(\mathrm{OMe})_{3}$ & $75 \%$ \\
\hline 11 & $2-\mathrm{I}$ & $\mathrm{NH}_{2}$ & $\mathrm{PPh}_{3}$ & $\mathrm{PhSi}(\mathrm{OMe})_{3}$ & $82 \%$ \\
\hline 12 & $2-\mathrm{I}$ & $\mathrm{NO}_{2}$ & $\mathrm{PPh}_{3}$ & $\mathrm{PhSi}(\mathrm{OMe})_{3}$ & $58 \%$ \\
\hline
\end{tabular}

Interestingly, a large decrease in yield occurred when the catalyst loading was dropped below 10 mol\%. In unhindered substrates, we have previously found this methodology to be tolerant of catalyst loadings as low as $3 \mathrm{~mol} \%$.

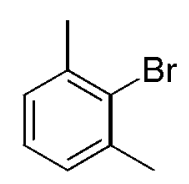

1

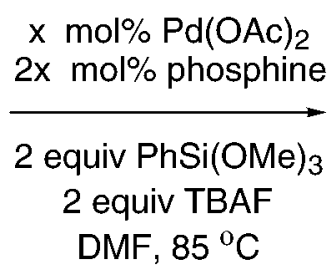

$$
\mathrm{x}=5 \mathrm{~mol} \%
$$$$
\mathrm{x}=10 \mathrm{~mol} \%
$$<smiles>Cc1cccc(C)c1-c1ccccc1</smiles>

2

$21 \%$

$85 \%$

Scheme 1

While coupling proceeds efficiently with a wide variety of aryl iodides, bromides, and chlorides, little work has been undertaken to determine the tolerance of the methodology toward substituted siloxanes. Consequently, several substituted siloxanes were synthesized using a modified procedure of Masuda [20]. These siloxanes were subjected to cross coupling conditions identical to that described in Table 1. Acceptable yields of biaryl adducts were obtained in all examined cases. 
Table 2 Cross couplings with substituted siloxanes.

\begin{tabular}{|l|l|l|l|}
\hline entry & siloxane & yield \\
\hline 1 & & \\
\hline 2 & & \\
\hline
\end{tabular}

\section{CONCLUSIONS}

This work further demonstrates the versatility and generality of the fluoride-mediated siloxane cross coupling methodology. Electron-rich iodo- and bromoanilines undergo cross coupling, as does electrondeficient 1-bromo-2-nitrobenzene. The ability of this methodology to tolerate sterically-challenged systems is also demonstrated, as well as couplings to substituted siloxanes.

Additional studies underway involve the coupling of heteroaromatic systems. Preliminary results of the cross coupling of 5-bromoindole (3) afford heterocoupled product 4 in $65 \%$ yield (Scheme 2). An interesting byproduct of the reaction involving phenyltrimethoxysilane is indole (5). Optimization of this reaction, as well as couplings of 2-bromothiazole and 4-bromopyrazole are currently under investigation. 
<smiles>Brc1ccc2[nH]ccc2c1</smiles>

3

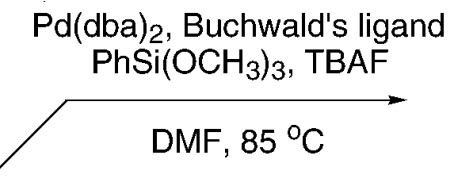

$\mathrm{Pd}(\mathrm{dba})_{2}$, Buchwald's ligand $\mathrm{PhSi}\left(\mathrm{OCH}_{2} \mathrm{CF}_{3}\right)_{3}$, TBAF<smiles>c1ccc(-c2ccc3[nH]ccc3c2)cc1</smiles><smiles>c1ccc(-c2ccc3[nH]ccc3c2)cc1</smiles>

$4,65 \%$

Scheme 2

Studies involving the preparation of a wide variety of substituted siloxanes and their application in the siloxane cross coupling methodology are also underway and will be reported in due course.

\section{REFERENCES}

1. B. M. Trost and T. R. Verhoeven. In Comprehensive Organometallic Chemistry, G. Wilkinson and F. G. A. Stone (Eds.), Vol. 8, pp. 799-938, Pergamon, Oxford (1982).

2. K. Tamao. In Comprehensive Organic Synthesis, B. M. Trost and I., Fleming (Eds.), Vol. 3, pp. 435-480, Pergamon, Oxford (1991).

3. D. W. Knight. In Comprehensive Organic Synthesis, B. W. Trost and I. Fleming (Eds.), Vol. 3, pp. 481-578, Pergamon, Oxford (1991).

4. T. Tsuji. Palladium Reagents and Catalysts. Innovations in Organic Synthesis, Wiley, New York (1995).

5. J. K. Stille, A. M. Echavarren, R. M. Williams, J. A. Hendrix. Org. Synth. 71, 97-106 (1992) and references therein.

6. N. Miyaura and A. Suzuki. Chem. Rev. 95, 2457-2483 (1995).

7. M. E. Mowery and P. DeShong. J. Org. Chem. 64, 3266-3270 (1999).

8. M.-R. Brescia and P. DeShong. J. Org. Chem. 63, 3156-3157 (1998).

9. A. S. Pilcher and P. DeShong. J. Org. Chem. 61, 6901-6905 (1996).

10. S. E. Denmark and Z. Wu. Org. Lett. 1, 1495-1498 (1999).

11. S. E. Denmark and J. Y. Choi. J. Am. Chem. Soc. 121, 5821-5822 (1999).

12. T. Hiyama. In Metal-Catalyzed Cross-Coupling Reactions, F. Diedrich and P. J. Stang (Eds.), pp. 421-452, Wiley-VCH, Weinheim, Germany (1998) and references therein.

13. K. A. Horn. Chem. Rev. 95, 1317-1350 (1995).

14. C. Chuit, R. J. P. Corriu, C. Reye, J. C. Young. Chem. Rev. 93, 1317-1448 (1993).

15. M. E. Mowery and P. DeShong. Org. Lett. 1, 2137-2140 (1999).

16. J. P. Wolfe and S. L. Buchwald. Angew. Chem., Int. Ed. Engl. 38, 2413-2416 (1999).

17. B. H. Yang and S. L. Buchwald. J. Organomet. Chem. 576, 125-146 (1999).

18. D. W. Old, J. P. Wolfe, S. L. Buchwald. J. Am. Chem. Soc. 120, $9722-9723$ (1998).

19. A. Aranyos, D. W. Old, A. Kiyomori, J. P. Wolfe, J. P. Sadighi, S. L. Buchwald. J. Am. Chem. Soc. 121, 4369-4378 (1999).

20. M. Murata, K. Suzuki, S. Watanabe, Y. Masauda. J. Org. Chem. 62, 8569-8571 (1997). 